Supporting Information Part B for

\title{
Imidazole-Functionalized Y-Shaped Push-pull Dye for Nerve Agent Sensing as well as a Catalyst for their Detoxification
}

\footnotetext{
Nilanjan Dey, ${ }^{[a]}$ Jiří Kulhánek, ${ }^{[b]}$ Filip Bureš, ${ }^{[b] *}$ and Santanu Bhattacharya*[c],[d],[e]

${ }^{[a]}$ Department of Chemistry, Birla Institute of Technology and Science-Pilani, Hyderabad, Telangana500078

${ }^{[b]}$ Institute of Organic Chemistry and Technology, Faculty of Chemical Technology, University of Pardubice, Studentská 573, Pardubice, CZ-53210, Czech Republic

${ }^{[c]}$ Department of Organic Chemistry, Indian Institute of Science, Bangalore 560012, Karnataka, India

[d] School of Applied and Interdisciplinary Sciences, Indian Association for Cultivation of Science, Kolkata 700032, India

[e]Jawaharlal Nehru Centre for Advanced Scientific Research, Jakkur, Bengaluru 560064, Karnataka, India

*Email:sb@iisc.ac.in
} 
Table of Contents

\begin{tabular}{|l|l|l|}
\hline Entry & Contents & Page Number \\
\hline 1 & ${ }^{1} \mathrm{H}-\mathrm{NMR}$ spectrum of $\mathbf{1}(5 \mathrm{mM})$ in DMSO- $\mathrm{d}_{6}$ medium & $\mathrm{S} 3$ \\
\hline 2 & ${ }^{13}$ C-NMR spectrum of $\mathbf{1}$ in DMSO- $\mathrm{d}_{6}$ medium & $\mathrm{S} 4$ \\
\hline 3 & HRMS mass spectrum of $\mathbf{1}$ & $\mathrm{S} 4$ \\
\hline
\end{tabular}




\section{Characterizations of Compound 1}

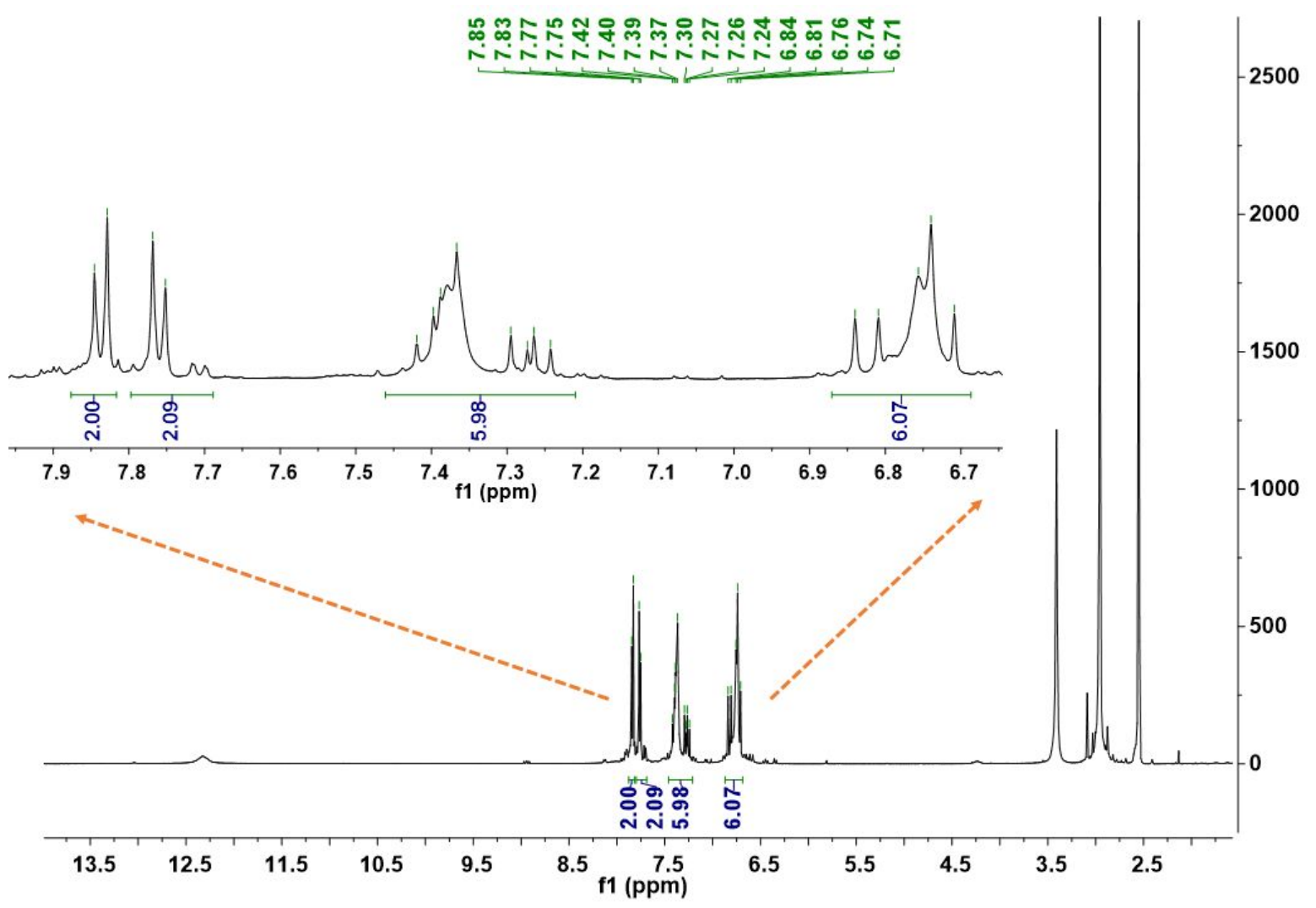

Figure S1. ${ }^{1} \mathrm{H}-\mathrm{NMR}$ spectrum of $\mathbf{1}(5 \mathrm{mM})$ in $\mathrm{DMSO}^{-\mathrm{d}_{6}}$ medium. 


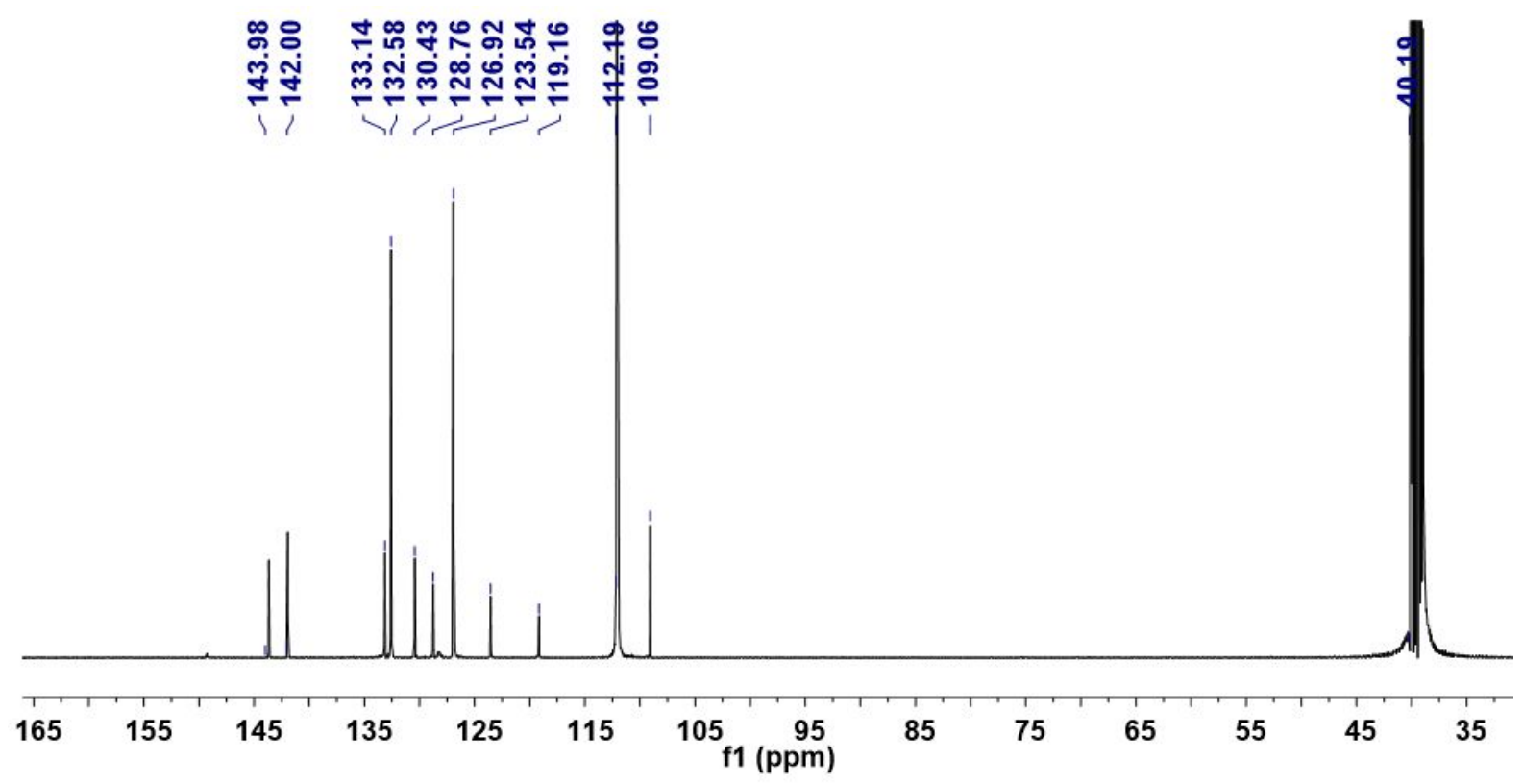

Figure S2. ${ }^{13} \mathrm{C}\left\{{ }^{1} \mathrm{H}\right\}$ spectrum of $\mathbf{1}$ in DMSO-d $\mathrm{d}_{6}$ medium.

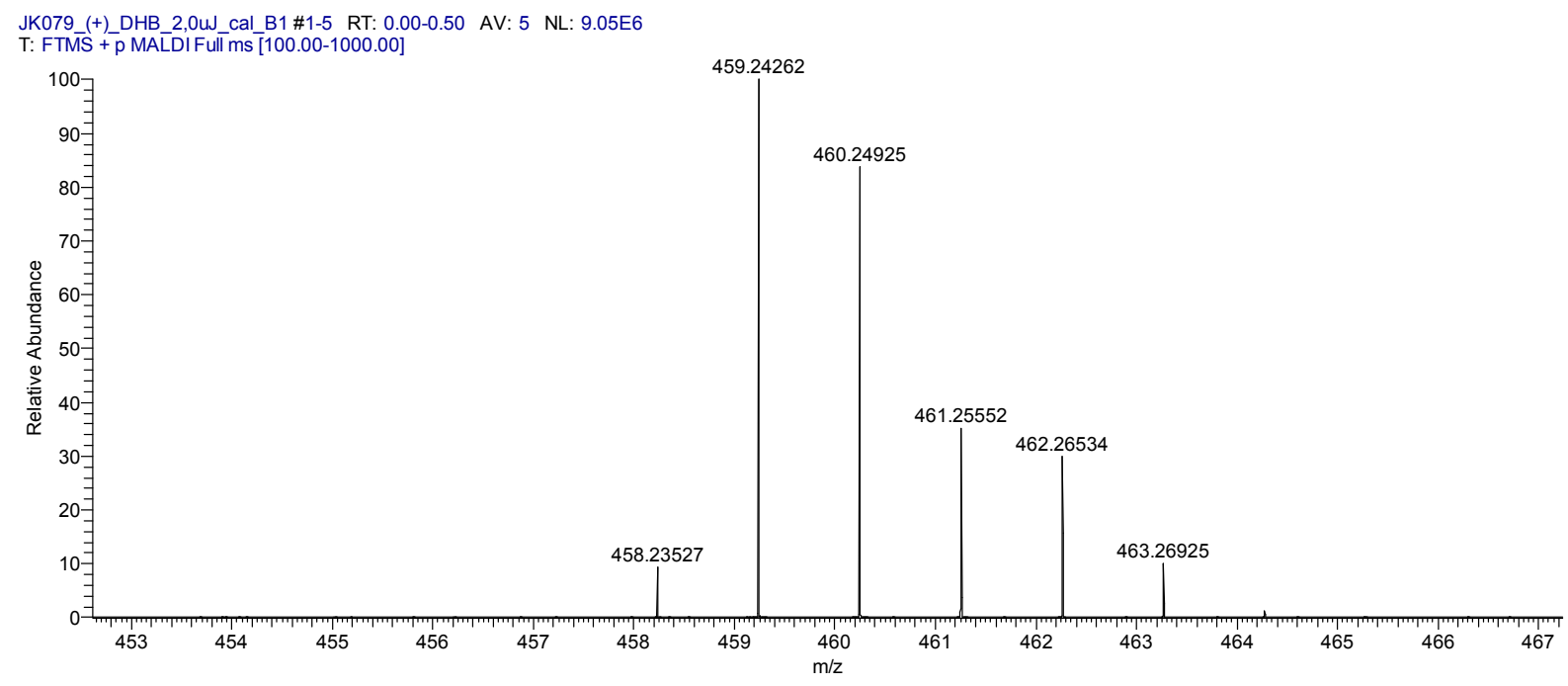

Figure S3. HR-FT-MALDI-MS mass spectrum of $\mathbf{1}$. 